\title{
Treatment of a Class 2 biproalveolia in a patient of Burkinabe origin
}

\author{
B. Ducroz ${ }^{1}$, O. Sorel ${ }^{2}$
}

1 Qualified Specialist in ODF [Orofacial Odontologist], University Hospital Assistant, Université Rennes 1, CHU [Centre Hospitlier Universitaire] Rennes

2 Qualified Specialist in ODF [Orofacial Odontologist], Professor of Universities - Hospital Practitioner, Université Rennes 1, CHU [Centre Hospitalier Universitaire] Rennes

\section{INTRODUCTION}

Débora was seen for the first time in the Orthodontic Department of the Dental Care Center in Rennes in May 2012. She was aged 13 years 10 months on the consultation day. Her family situation was complicated; she was a political refugee and her parents were still in Burkina Faso, Africa. She came for a consultation to the orthodontic service because she felt that her two maxillary canines were too far forward. Due to her ethnic origins, Débora posed a reference problem regarding the positioning of her teeth, which made it more difficult to determine whether her condition was due to her ethnicity or pathological (alveolar protrusion or asymmetrical jaw).

\section{EXTRAORAL EXAMINATION}

\section{Face (Fig. 1)}

Débora presented with an oval and elongated face. The median sagittal axis was not rectilinear; the chin was deviated to the left, and the palpation of the mandibular angle was higher on the left. The ophriac, bipupillary, and bicommissural lines were convergent toward the left. The lips were thick. The bilabial contact was spontaneous. The chin was deviated to the left.
Mailing address:

Bertrand Ducroz - Le Patis Tatelin - 35700 Rennes

E-mail: ducroz_bertrand@hotmail.com
Article received: 26-08-2016. Accepted for publication: 15-09-2016.

This is an Open Access article distributed under the terms of the Creative Commons Attribution License (http://creativecommons.org/licenses/by/4.0), which permits unrestricted use, distribution, and reproduction in any medium, provided the original work is properly cited. 


\section{Profile (fig. 2)}

The face was convex. The subnasal profile was transfrontal. The nasolabial angle was $70^{\circ}$. The lips were fleshy, and the upper lip was in procheilia in relation to the esthetic line of Ricketts. The lower lip was everted. We observed biprocheilia. The nasolabial groove was scarcely marked. The labiomental groove was marked. The chin was slightly back and taut. The cervical-chin distance was normal. The bottom of the face was augmented.

\section{Smile (fig. 3)}

The upper lip was flush with the collar of the maxillary incisors. The smile was asymmetrical, with the right side revealing more than the left. The maxillary canines broke the harmony of the smile. The maxillary and mandibular backgrounds were deviated.

\section{EXAMINATION OF FUNCTIONS}

The patient presented with nasal ventilation, adult swallowing, and correct phonation. Mastication was alternate one-sided. The tongue had the right shape, normal mobility, and normal posture. She had a good head carriage.

Débora did not have any parafunctions.

The opening and closing pathways were deviated with slight joint laxity.

There was no clapping or perceptible crackling. There was also no muscle pain.

\section{INTRAORAL EXAMINATION}

Débora did not have tooth decay, but she had occlusal restorations on 16, 26,36 , and 46 . Her oral hygiene was

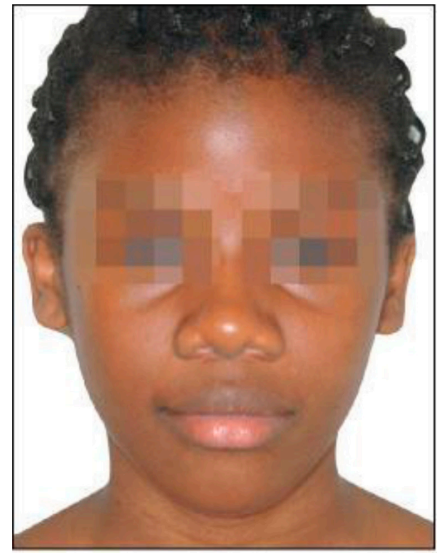

Figure 1

Photograph of the face.

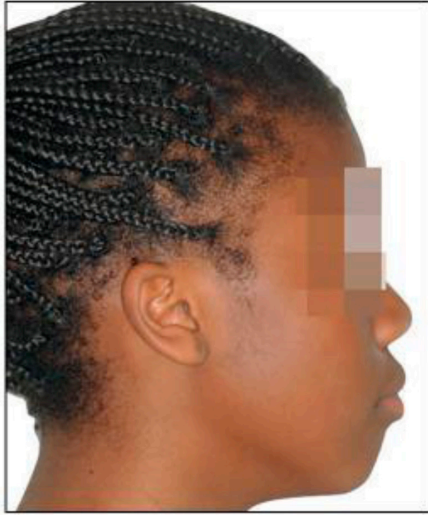

Figure 2

Photograph of the profile.

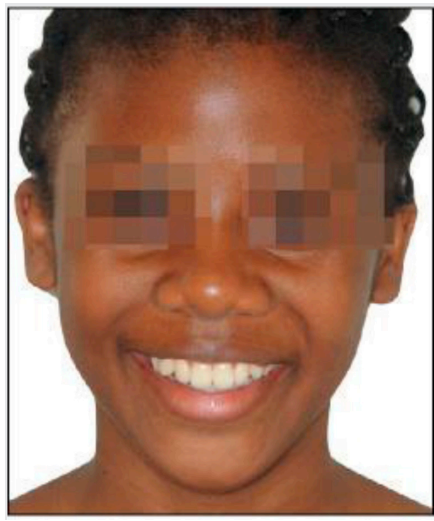

Figure 3

Photograph of the smile. 
satisfactory. The attached gingiva was present and was the correct height and thickness (Wilson type I.)

Her dental age corresponded to her actual age. Débora had a stable set of teeth consistent with the young adult phase according to Demogé.

We noted oral-dental harmony: the anterior Bolton index was 77\% (norm: $77 \%)$ for the incisivo-canine block.

\section{Maxillary arch (Fig. 4)}

The general shape of the arch was parabolic and globally symmetrical. We noted incisivo-canine congestion. The Wilson curve was not very marked. The palatal vault was sufficiently wide and deep.

\section{Mandibular arch (Fig. 5)}

The general shape of the arch was asymmetric with lingualization of sector 3. The arrow of the curve of Spee was $0 \mathrm{~mm}$ to the right and $1 \mathrm{~mm}$ to the left. The mandibular size was $4 \mathrm{~mm}$, and the mandible was located at the level of 35.

\section{Interarch examination (Fig. 6)}

The incisal overhang was slightly insufficient, particularly in the lateral and canine incisors, even if the incisal overlap (central) was $2 \mathrm{~mm}$. The examination revealed a Class I molar and canine to the right, but a Class II molar and canine were $2 \mathrm{~mm}$ further to the left. The interincisal points were not concordant; the mandibular point was deviated to the left by $2 \mathrm{~mm}$. There was temporary infraclusia of teeth 15, 25, 13, 23, and 24, which were in the process of eruption.

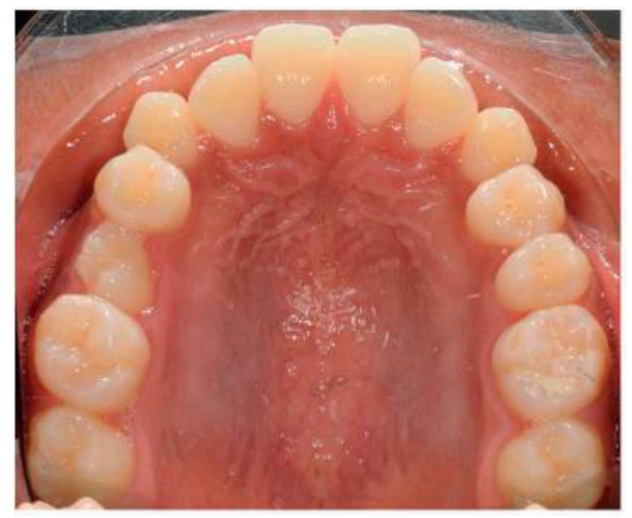

Figure 4

Intraoral photograph of the maxilla showing a globally symmetrical and parabolic arcade with some malpositions.

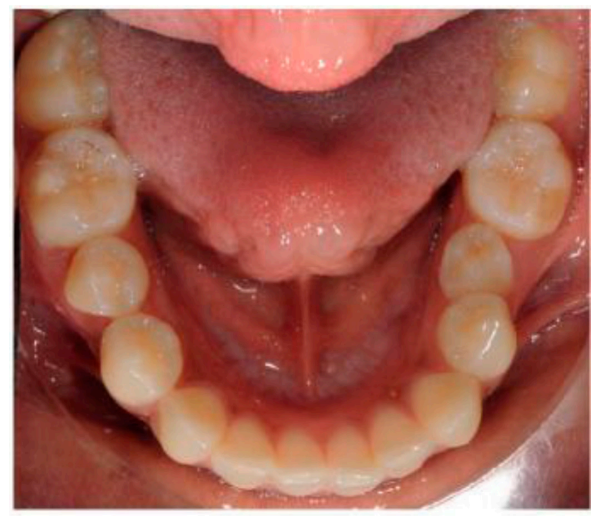

Figure 5

Intraoral photograph of the mandible showing a slightly asymmetrical arch with an obstruction located mainly in sector 3 .
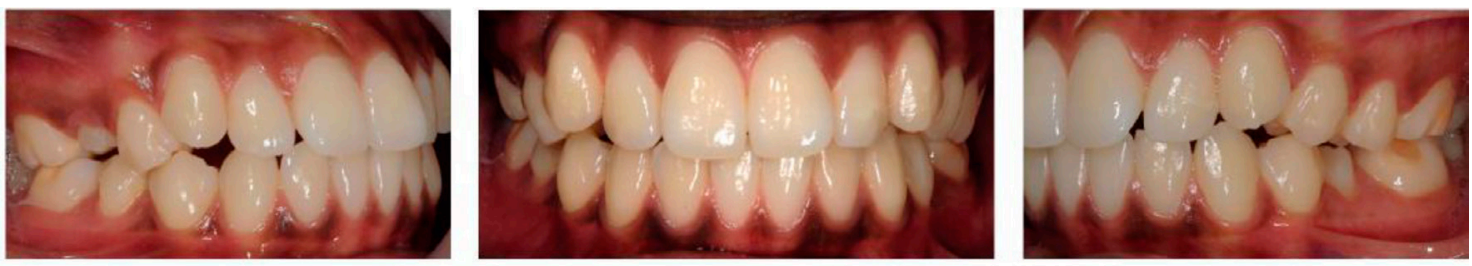


\section{RADIOGRAPHS}

\section{Panoramic (Fig. 7)}

The condyles appeared morphologically normal. The images of the maxillary sinuses did not show any pathologies.

Her bone tissue did not exhibit pathological images. All her permanent teeth were visible. The plaque layer of the third maxillary and mandibular molars were visible, and the crowns were in developmental progress. Tooth 15 presented dwarfism.

\section{Teleradiography of the face}

(Fig. 8)

The interincisive points were not concordant. The mandibular point was deviated to the left. The left mandibular angle was lower than the right. The pyriform orifices were pear-shaped. The radiographic image between the mandibular and maxillary ascending branches was of moderate size and did not seem to signal maxillary endognathy. The chin was deviated to the left, in agreement with the clinical examination result.

\section{Teleradiography of the profile (Figs. 9 and 10)}

At the skeletal level, the angle GoGn-SN at $38^{\circ}$ and the angle O-SN at $20^{\circ}$ indicated hyperdivergence. The SNA was greater than the norm value, whereas the SNB was within the norm value. The angle ANB was at $8^{\circ}$, which was higher than the norm and the AoBo was at $0 \mathrm{~mm}$. Skeletal relationships were those of a Class II bipromaxillia. Dental values indicated that the mandibular incisors were strongly vestibulo-positioned and had increased inclination. The distances between the upper and lower lips and the esthetic line of Steiner increased, indicating a biprochelia, which can be attributed to its ethnic origin. The SE$S L$ values showed a normal mandible.

We compared the data of Steiner cephalometry established according to an American standard with the reality of the

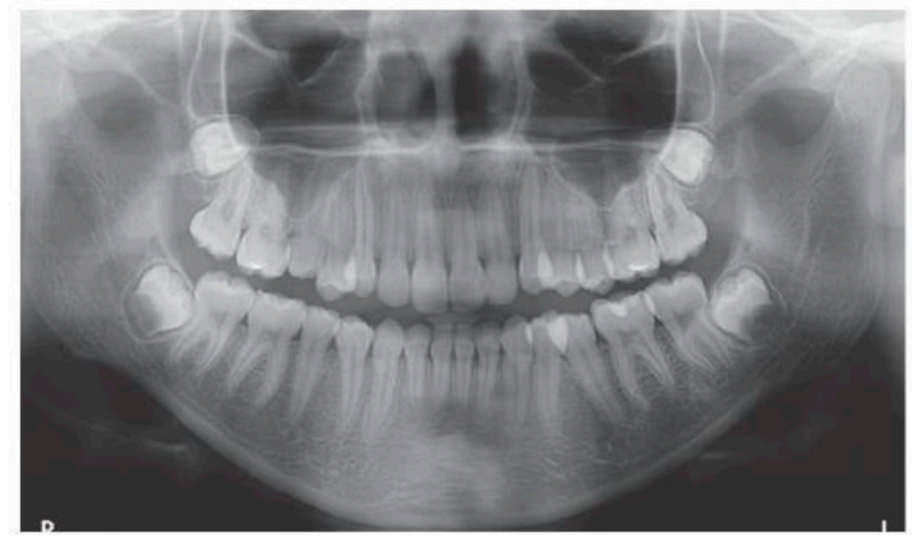

Figure 7

Panoramic radiograph at the start of treatment. 


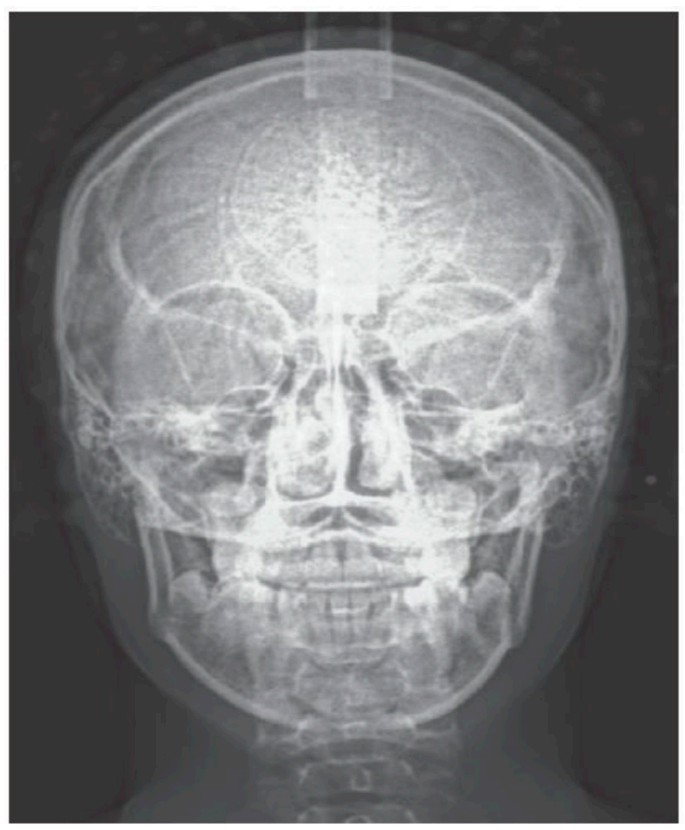

Figure 8

Radiograph of the face at the start of treatment.

clinical examination of the face, particularly the intraoral and periodontal regions, to locate the desirable position for the

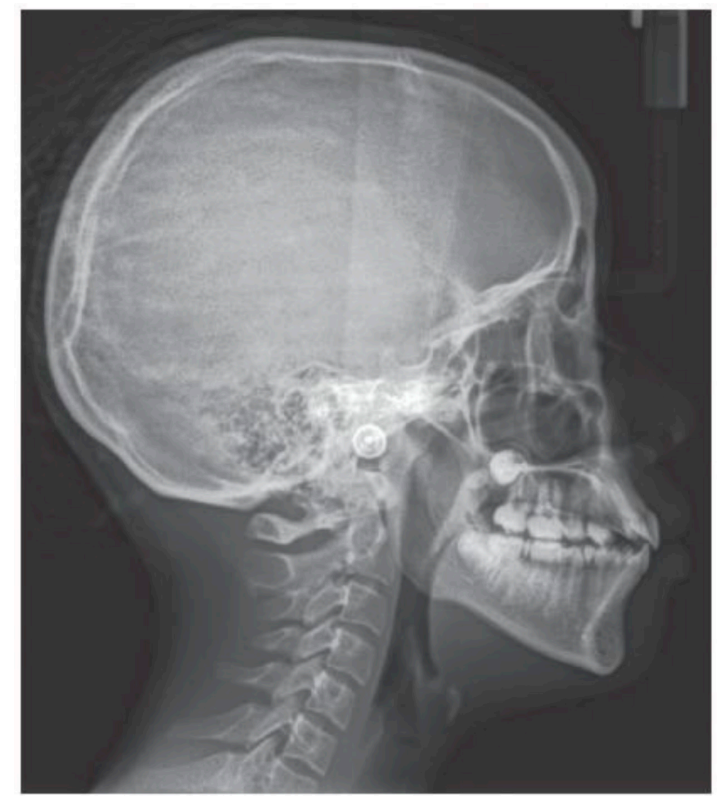

Figure 9

Radiograph of the profile at the start of treatment.

teeth. This should be done regardless of the patient and particularly in the case of Débora, whose was of Burkinabe origin.

\section{MADIAGNOSTIC SUMMARY}

Our clinical examination made it possible to make the following diagnosis for Débora: this was a case of Class II.1 left subdivision. The facial typology was hyperdivergent, and the skeletal

\section{TREATMENT PLAN}

\section{Objectives}

The objective was to correct the Class II subdivision and associated

sagittal shift was Class II. The dentoalveolar context was marked by strong biproalveolia. The latter helps confirm the dentoalveolar compensation of Class II in ethnic biproalveolia.

dentoalveolar compensations. There was the problem of the correction of biproalveolia, its psychosocial involvement, its repercussions on the 
Results of Steiner analysis

\begin{tabular}{|c|c|c|c|c|}
\hline & & & Ideal & $05 / 2012$ \\
\hline \multirow[t]{3}{*}{ Skeletal } & $\begin{array}{l}\text { Vertical } \\
\text { direction }\end{array}$ & GoGn-SN $\left({ }^{\circ}\right)$ & 32 & 38 \\
\hline & & $0-\operatorname{SN}\left({ }^{\circ}\right)$ & 14 & 20 \\
\hline & & & Ideal & $05 / 2012$ \\
\hline \multirow[t]{7}{*}{ Skeletal } & $\begin{array}{l}\text { Sagittal } \\
\text { direction }\end{array}$ & $\operatorname{SNA}\left({ }^{\circ}\right)$ & 82 & 90 \\
\hline & & $\operatorname{SNB}\left({ }^{\circ}\right)$ & 80 & 82 \\
\hline & & $\operatorname{SND}\left({ }^{\circ}\right)$ & 76 & 79 \\
\hline & & ANB $\left({ }^{\circ}\right)$ & 2 & 8 \\
\hline & & AoBo (mm) & 0 & 1 \\
\hline & & SE (mm) & 22 & 20 \\
\hline & & SL (mm) & 51 & 53 \\
\hline
\end{tabular}

\begin{tabular}{|l|l|c|l|}
\cline { 3 - 4 } \multicolumn{2}{l|}{} & Ideal & $05 / 2012$ \\
\hline Dental & I-NA (mm) & 4 & 5 \\
\hline & I-NA $\left(^{\circ}\right)$ & 22 & 21 \\
\hline & i-NB (mm) & 4 & 12 \\
\hline & i-NB $\left({ }^{\circ}\right)$ & 25 & 36 \\
\hline & i-I $\left(^{\circ}\right)$ & 131 & 114 \\
\hline & Pog-NB (mm) & - & 0 \\
\hline & i-NB - Pog-NB (mm) & - & 12 \\
\hline
\end{tabular}

\begin{tabular}{|l|c|c|l|}
\cline { 3 - 4 } \multicolumn{2}{c|}{} & Ideal & $05 / 2012$ \\
\hline Esthetic & Upper lip/line S & 0 & +2 \\
\hline & Lower lip / line S & 0 & +4 \\
\hline
\end{tabular}

Figure 10

Cephalometric analysis at the start of treatment.

volume of the mouth, and its adequacy with the tongue. Particular attention was brought to the mechanics set up in this context of hyperdivergence.

\section{Methods}

1) The diagnosis of dentomaxillary disharmony was made with the consequence of the extraction decision. In this context, it proved impossible to preserve the complete set of teeth; the clutter, the correction of the Class II, and even the moderate correction of the biproalveolia were not compatible with treatment without extraction. The second premolars presented forms at the limit of dysmorphy, which, in this context, made us indicate their extraction.

2) The management of the maxillary and mandibular multiring in this hyperdivergent context presented a critical problem in the management of extraction spaces. The present spaces allowed us to manage all problems of the arcade relatively easily. The biomechanical problems of loss of anchorage were important here, thus presenting an iatrogenic risk.

The anchorage of the sectors behind the maxilla was maximum; hence, anchor reinforcements by screwed anchors were used.

3) Finishing touches

4) Contention and stabilization 


\section{Alignment Phase}

$1^{\text {st }}$ RDV: maxillary collage, arc NiTi .014 .

$2^{\text {nd }} \mathrm{RDV}$ : mandibular collage, arc $\mathrm{NiTi}$ .014 to the lower arch and NiTi .016 to the maxilla.

$3^{\text {rd }}$ RDV: NiTi .018 To the two arcades.

$4^{\text {th }}$ RDV: ATP and NiTi $.020 \times .020$ to the two arcades.

\section{Closing of spaces}

September 2013 (Figs. 11 and 12): the closing phase of the spaces was initiated on steel arc $.019 \times .025$. A sliding mechanism was used here. Anchorage control was done with the transpalatal arc connected to miniscrews placed distal to 16 and 26 (anchorage). At the mandible, the closing of spaces was done by loss of posterior anchorage, thus favoring the establishment of a relationship between Class I molar and recoil and linguoversion of the anterior sector.

\section{Finishing touches}

June 2014 (Figs. 13 and 14): end of the closing of spaces and beginning of the finishes. These were undertaken with arcs TMA $.018 \times .025$.

Radiological reassessment on June 2014 (Figs. 15, 16, and 17): extractions allowed treatment without the iatrogenic effect of aggravation of the biproalveolia.

The Class I occlusion with a covering (without a gap) confirmed our therapeutic choices of the position of the incisors (although the incisors were hypercorrected).

If the results were convincing in this case, they were the result of a gamble; in other words, a therapeutic option that we were not certain would work was used. Space management, particularly through bone anchors, has been proven to be quite effective. The wearing of intermaxillary elastics has been reduced to the shortest time necessary; their interference effect also has been reduced, particularly the effect on vertical interference.

\section{END OF ACTIVE TREATMENT AND RESTRAINT}

December 2014 (Figs. 18, 19, 20, 21, and 22): Removal of the multifastening apparatus and installation of the restraint. The choice of a braided titanium bonded wire of 12 to 22 and 33 to 43 guarantees the stability of the alignment of the supported sectors. The duration of bonded restraint depends on the wish of patients to retain the alignment of the supported areas. The extractions of the premolars allowed the establishment of a Class I angle without a proiatrogenic version. The profile was not retroactive. The maxillary molar was not mesial (see local superposition), but it moved downward and forward due to facial growth (see the overlay on the base of the skull). On this superimposition, we saw 

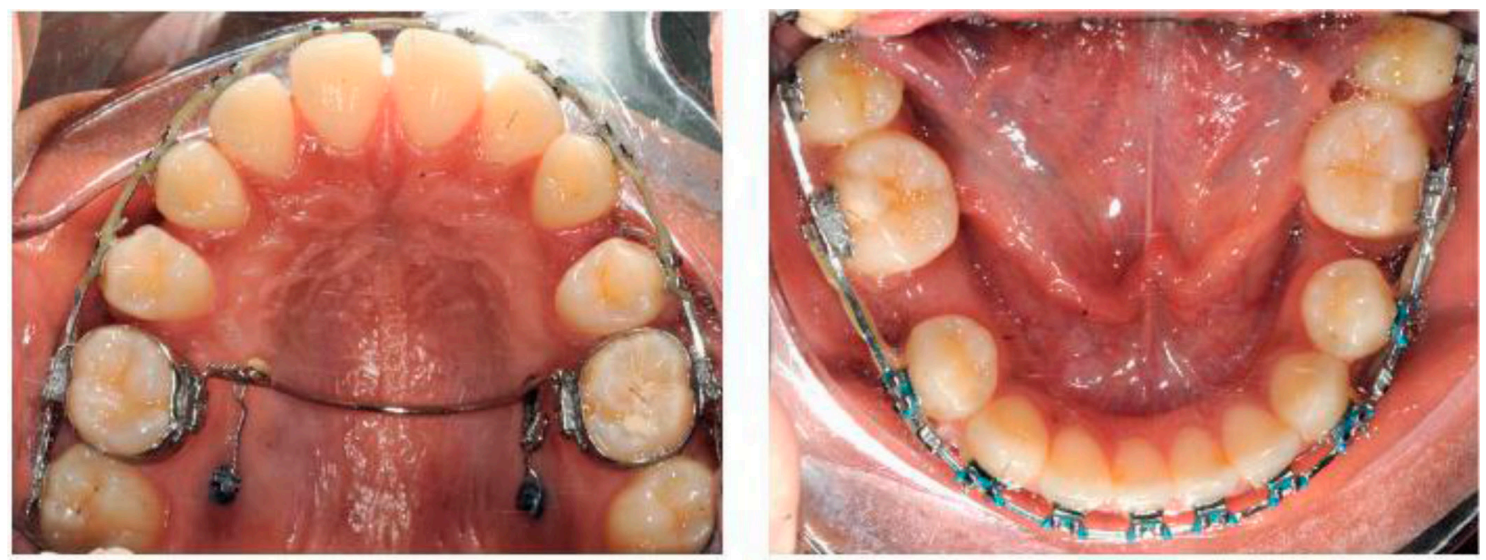

Figure 11

Intraoral photographs (closing of spaces). The anchorage of the posterior maxillary areas is ensured by two miniscrews attached to the ATP. In the mandible, a reciprocal closure system was used that has the advantage of centralizing the posterior areas and positioning in Class I and the recoil of the anterior segment with a linguoversion component that aims to decompensate proalveolia.
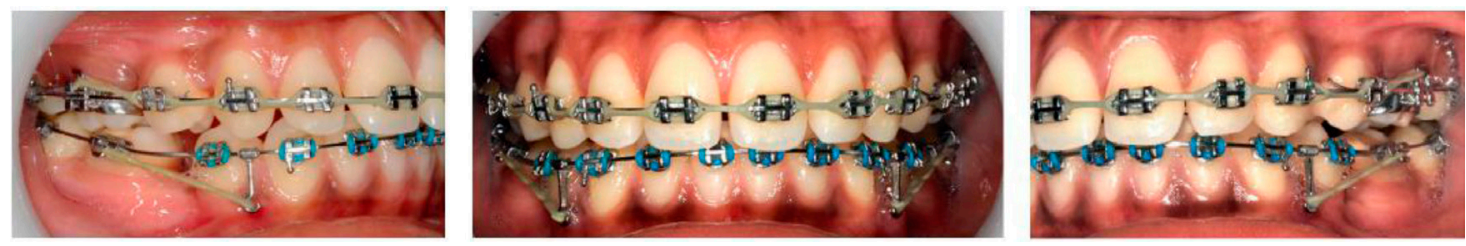

Figure 12

Intraoral lateral views (closing of the spaces). Reciprocal closure of mandibular spaces. A stem positioned between the premolar and canine allows lowering the threshold of application of the forces. It would have been preferable to install the same system of brackets at the molar level, but the depth of the vestibule did not allow it.
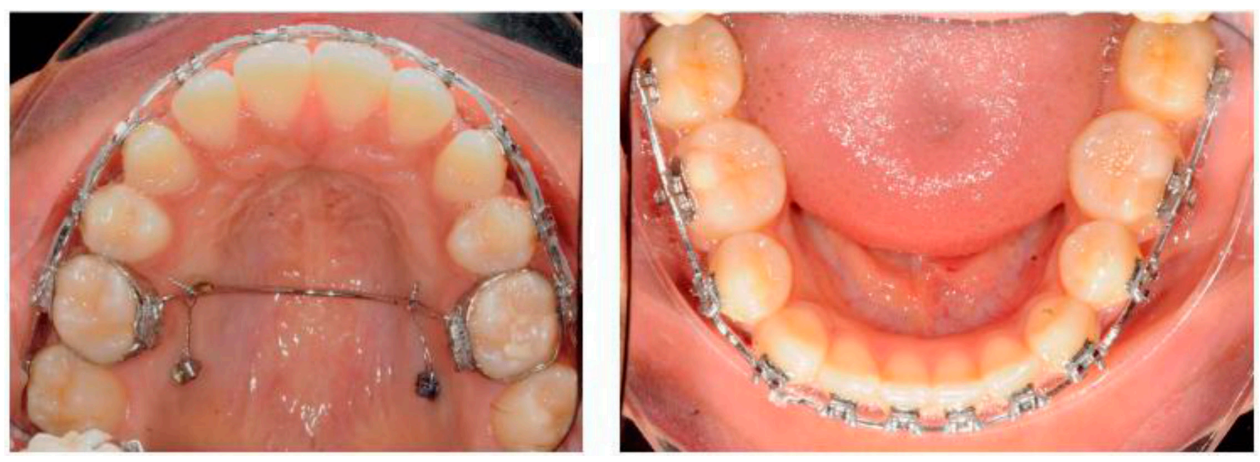

Figure 13

Intraoral photographs (closed spaces). The intra-arcade spaces are practically closed. 

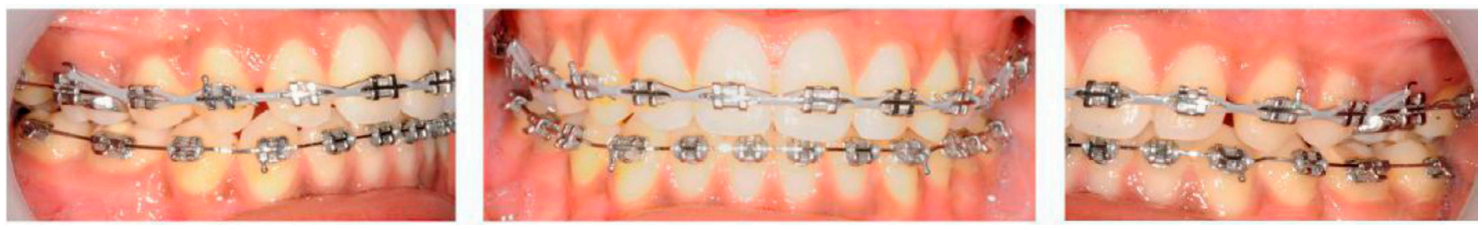

Figure 14

Intraoral photographs (closed spaces). The interarcade ratios are Class I. The treatment finish requires closing precanine spaces and possibly wearing the Class II elastic over a short period to ensure a good Class I angle.

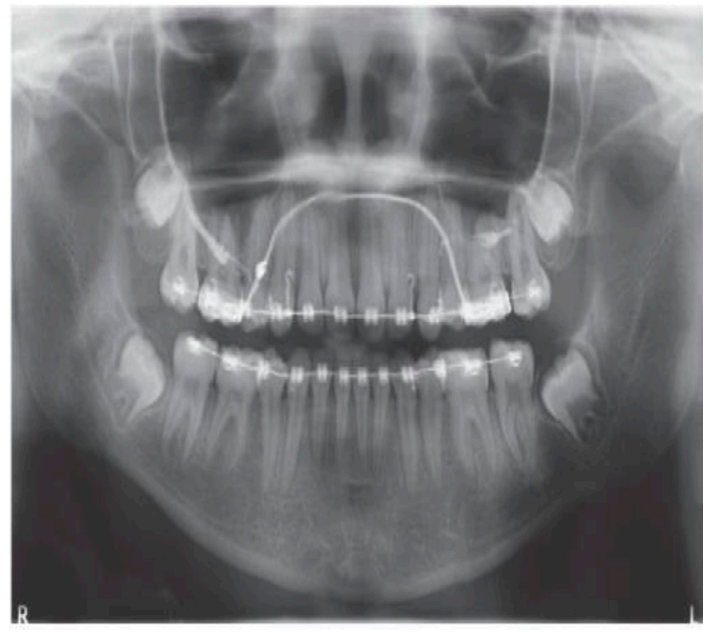

Figure 15

Panoramic radiograph; June 2014.

mandibular homothetic growth without facial aperture.

Radiographic analysis (Figs. 23, 24, 25 , and 26) showed no radicular resorption, with mandibular incisors well positioned in the symphysis with correct lip support. At the skeletal level, the GoGn-SN, O-SN, and O-SN angles slightly decreased, and practitioners feared that having an opening of the mandibular compass (without extraction) would become an issue. The ver-

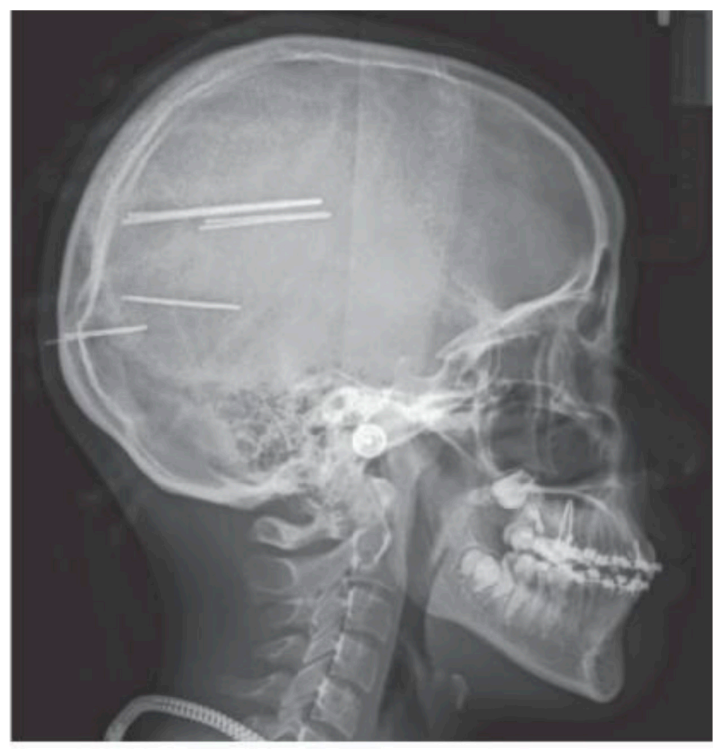

Figure 16

Teleradiography of the profile; June 2014.

tical effect of the screwed anchor can be the origin of this closure. Superstitions confirm this hypothesis. The SNB angle increased as the SNA decreased, which led to a decrease in the ANB angle. The axes of the incisors require the hypercorrection of the bipro alveolia. The profile of the patient was corrected, and the biprocheilia was corrected without excess. The ethnic characteristics of the fleshy lips (greater myofibrillar ratio than in Caucasians) 


\begin{tabular}{|c|c|c|c|}
\hline & VALUE & May 2012 & June 2014 \\
\hline SNA $\left({ }^{\circ}\right)$ & 82 & 90 & 91 \\
\hline SNB $\left({ }^{\circ}\right)$ & 80 & 82 & 85 \\
\hline ANB $\left({ }^{\circ}\right)$ & 2 & 8 & 6 \\
\hline Ao Bo $(\mathrm{mm})$ & 2 & 1 & 0 \\
\hline $\operatorname{SND}\left({ }^{\circ}\right)$ & 76 & 79 & 82 \\
\hline I to NA (mm) & 4 & 5 & 4 \\
\hline I to NA $\left({ }^{\circ}\right)$ & 22 & 21 & 15 \\
\hline i to NB (mm) & 4 & 12 & 5 \\
\hline i to NB $\left({ }^{\circ}\right)$ & 25 & 36 & 33 \\
\hline i to $1\left(^{\circ}\right)$ & 131 & 114 & 125 \\
\hline $\mathrm{Occ}^{\circ}$ to $\mathrm{SN}\left({ }^{\circ}\right)$ & 14 & 20 & 13 \\
\hline GoGn to $S N\left({ }^{\circ}\right)$ & 32 & 38 & 35 \\
\hline $\mathrm{SL}(\mathrm{mm})$ & 51 & 53 & 50 \\
\hline $\mathrm{SE}(\mathrm{mm})$ & 22 & 20 & 21 \\
\hline
\end{tabular}

Figure 17

Cephalometric analysis during treatment.

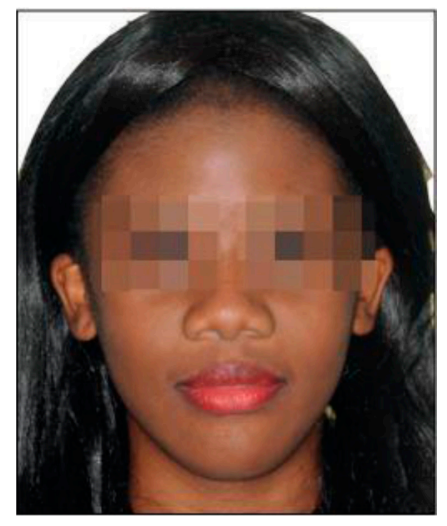

Figure 18

Extraoral photograph of the face (end of treatment).

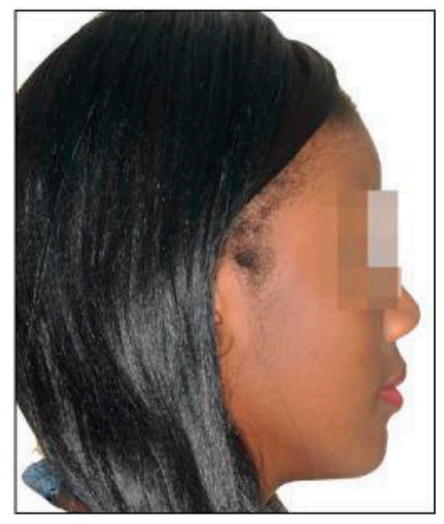

Figure 19

Extraoral photograph of the profile (end of treatment).

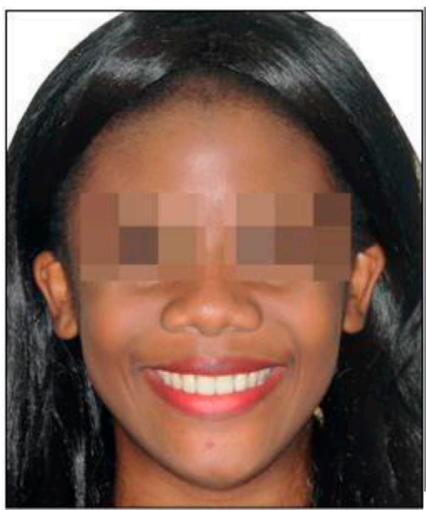

Figure 20

Extraoral photograph of the smile (end of treatment). 

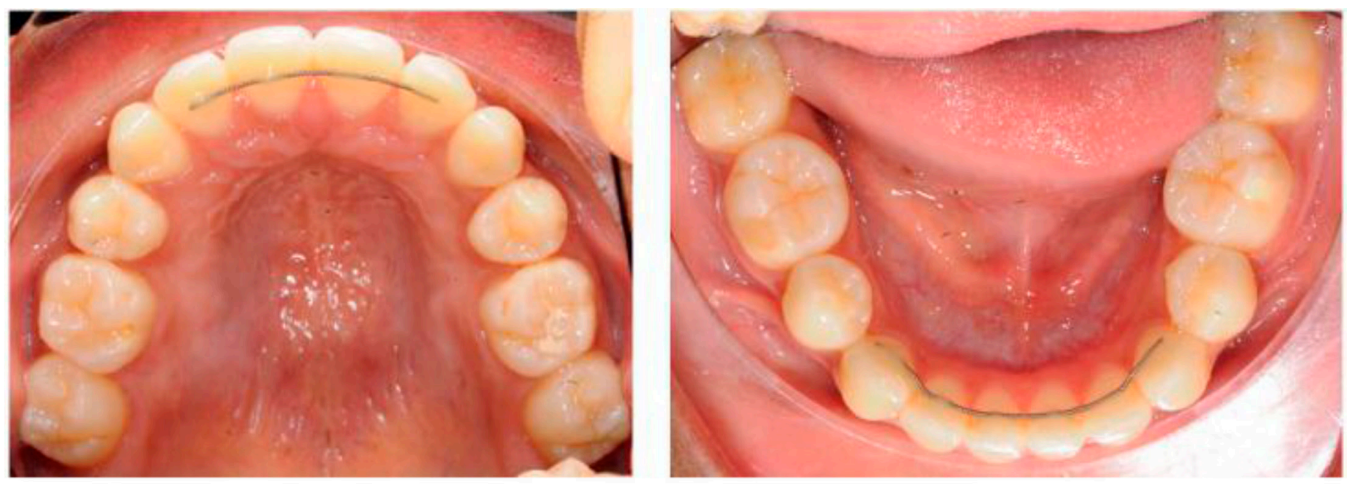

Figure 21

Occlusal photographs (end of treatment).
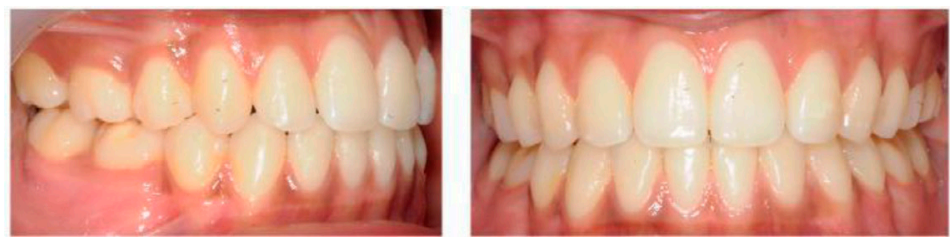

Figure 22

Intraoral photographs (end of treatment). If the different occlusal criteria are generally ensured, it is important to note the good incisal covering, particularly in the canines and the lateral incisor, which was initially insufficient. The cause of initial insufficient recovery was likely related to the lack of space.

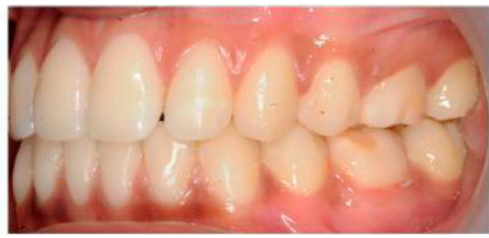




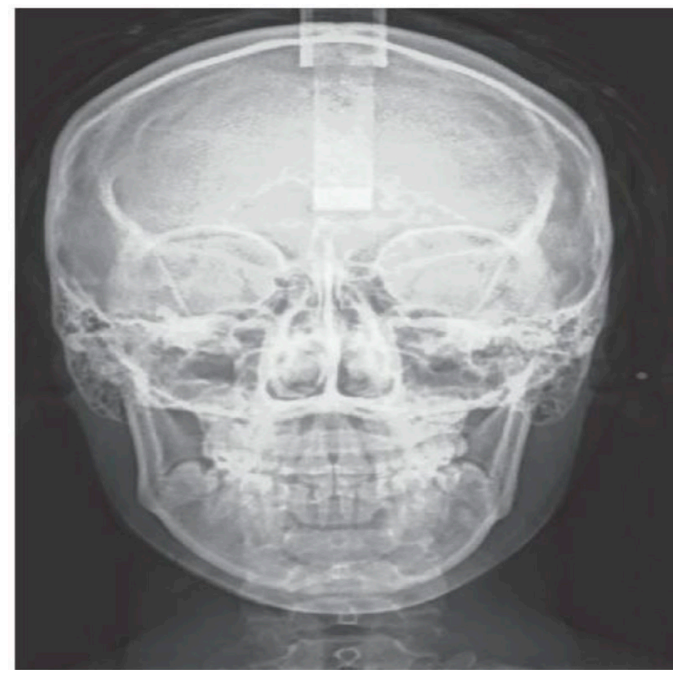

Figure 24

Radiograph of the face; December 2014.

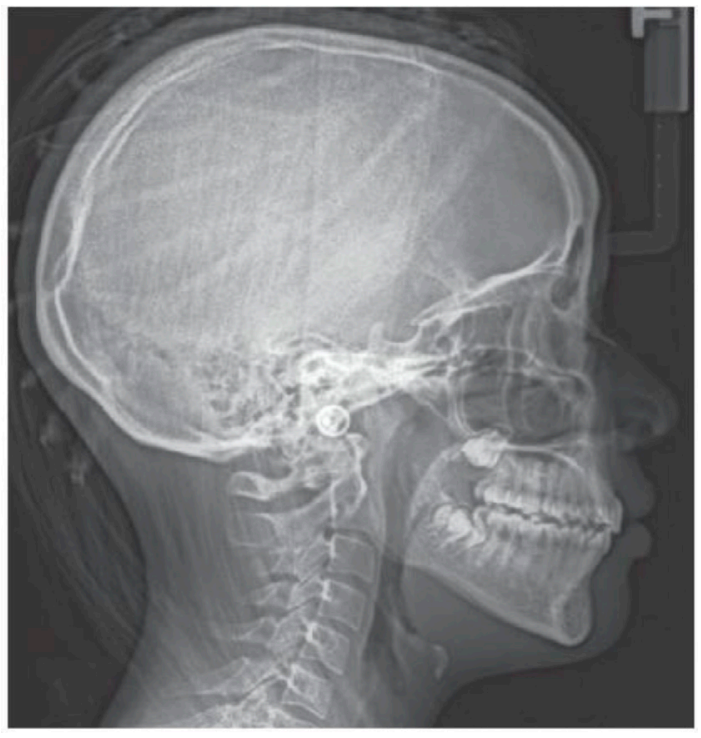

Figure 25

Radiograph of the face; December 2014.

\begin{tabular}{|l|l|l|l|l|}
\hline & VALUE & May 2012 & June 2014 & December 2014 \\
\hline SNA $\left(^{\circ}\right)$ & 82 & 90 & 91 & 89 \\
\hline SNB $\left(^{\circ}\right)$ & 80 & 82 & 85 & 84 \\
\hline ANB $\left(^{\circ}\right)$ & 2 & 8 & 6 & 5 \\
\hline Ao Bo $(\mathrm{mm})$ & 2 & 1 & 0 & 1 \\
\hline SND $\left(^{\circ}\right)$ & 76 & 79 & 82 & 81 \\
\hline I to NA $(\mathrm{mm})$ & 4 & 5 & 4 & 3 \\
\hline I to NA $\left(^{\circ}\right)$ & 22 & 21 & 15 & 16 \\
\hline i to NB $(\mathrm{mm})$ & 4 & 12 & 5 & 4 \\
\hline i to NB $\left(^{\circ}\right)$ & 25 & 36 & 33 & 29 \\
\hline i to I $\left(^{\circ}\right)$ & 131 & 114 & 125 & 130 \\
\hline Occ ${ }^{\circ}$ to SN $\left(^{\circ}\right)$ & 14 & 20 & 13 & 18 \\
\hline GoGn to SN $\left(^{\circ}\right)$ & 32 & 38 & 35 & 35 \\
\hline SL $(\mathrm{mm})$ & 51 & 53 & 50 & 51 \\
\hline SE $(\mathrm{mm})$ & 22 & 20 & 21 & 20 \\
\hline
\end{tabular}

Figure 26

End-of-treatment cephalometric analysis. 


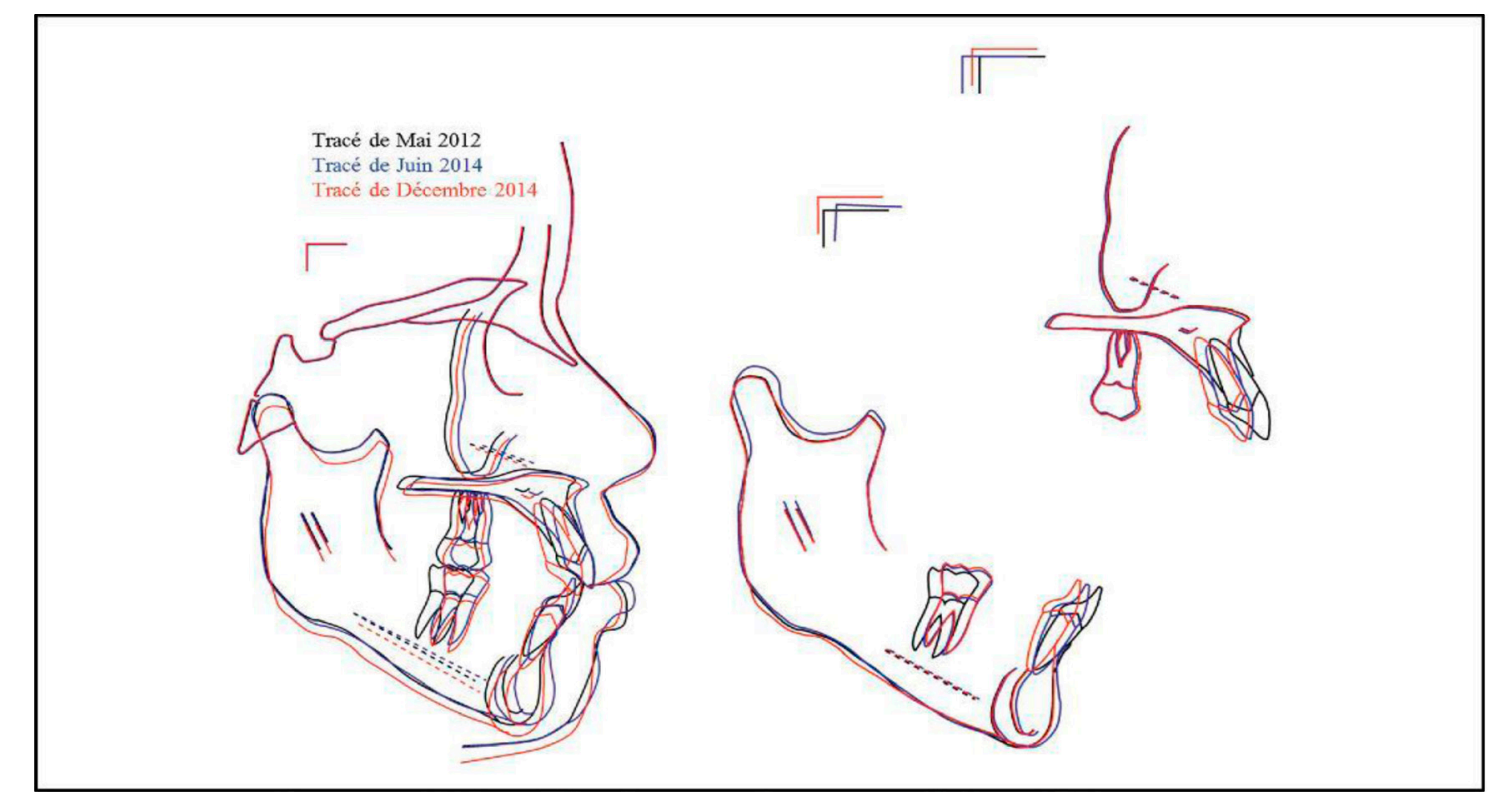

Figure 27

End-of-treatment overlay. Key: Trace of May 2012; Trace of June 2014; Trace of December 2014.

At the treatment level, the objectives were reached because it was possible to decrease the biproalveolia with respect to her flat profile. Débora had a Class I canine and molar with a full and esthetically pleasing smile. The extraction treatment did not markedly affect base divergence. The overall growth and, in particular, the mandibular growth were favorable; the ANB angle consistently decreased during the treatment.

This factor can be related to the restoration of maxillary incisors; however, it remains random. It is random in the sense that it seems impossible to predict favorable growth. However, we believe that repositioning allows growth to occur naturally.

At the end of treatment periodontal tissues were in good health and no defects were observed either in the extraction sites or in the fragile areas of the incisal vestibular areas. The extraoral images showed a balance of the face, which validates the therapeutic choices.

Therapeutic decisions are based on a precise and detailed diagnosis that considers all morphological, physiological, and ethnic data specific to patients. Therapeutic choices are much more subjective. They represent a gamble on our part that we have taken into account all parameters. Here the extraction decision and biproalveolia correction could have resulted in a reduction in the "tongue box" with a consequent aggravation of the gap (pre-existing at the canine level). The favorable growth that can be linked to incisive repositioning cannot be set up as a principle. In making the decision to extract, we first wanted to protect the periodontium by avoiding aggravation of vestibular versions.

Conflict of interest: The authors declare that there is no conflict of interest. 